\title{
A Combination of Teacher-Led Assessment and Self-Assessment Drives the Learning Process in Online Master Degree in Transplantation
}

\author{
Ahmed Halawa ${ }^{1 \& 2, *}$, Ajay Sharma ${ }^{2 \& 3}$, Julie M Bridson², Sarah Lyon ${ }^{2}$, Denise Prescott ${ }^{2}$, Arpan Guha ${ }^{2 \& 3}$ and David \\ Taylor ${ }^{3}$ \\ ${ }^{1}$ Sheffield Teaching Hospitals, Sheffield, UK \\ ${ }^{2}$ Faculty of Health and Life Science, Institute of Learning and Teaching, University of Liverpool, UK \\ ${ }^{3}$ Royal Liverpool University Hospitals, Liverpool, UK \\ *Correspondence: Consultant Transplant Surgeon, Sheffield Teaching Hospitals, Herries Road - Sheffield S5 7AU, \\ United Kingdom. Tel: 44-778-754-2128. E-mail: ahmed.halawa@sth.nhs.uk
}

Received: June 30, 2017

Accepted: August 11, $2017 \quad$ Online Published: August 20, 2017

doi:10.5430/wje.v7n4p85

URL: https://doi.org/10.5430/wje.v7n4p85

\begin{abstract}
Background: Good performance in a summative assessment does not always equate to educational gain following a course. An educational programme may focus on improving student's performance on a particular test instrument. For example, practicing multiple choice questions may lead to mastery of the instrument itself rather than testing the knowledge and its application. We designed an assessment strategy that consistently valid and reliable that would fit with the students with a range of 27 nationalities with a different institutional, cultural and educational background in this totally online masters programme in transplantation.
\end{abstract}

Methods: Based on the published evidence, we analyzed 2 main assessment domains: (a) self-assessment and (b) peer-assessment. We compared them with traditional teacher-led assessment considering the diversity of students.

Conclusion: We conclude that traditional teacher-led assessment supplemented by self-assessment is a strong drive in the learning process in this on-line course, whilst peer-assessment is challenging and associated with many flaws giving the diversity of our students. Peer-assessment may be unreliable and not valid due to the difference in the institutional background and variation in experience between the students.

Keywords: self-assessment; peer-assessment; teacher-led assessment; distance learning; transplantation; and clinical education

\section{Introduction}

During undergraduate education, most of us dreamt of an education system that would be without the stress of exams wherein a regular assessment of our performance in the classroom would be deemed good enough to let us progress to the next year. That 'imaginary' education made us feel 'she smiles at me and I am seventeen again', though far from reality. In contrast, the reality has been that we had to undergo a battery of (read it battering by) summative tests after tests and, therefore, the educational process transformed to be an assessment-orientated exercise. While the summative assessment used to give us anxiety (to say least), but in retrospect we appreciate that the anxiety was one of main drivers for our learning. As a result of that self-imposed drive and the pressure of expectations by family and society, we worked hard to pass the exams but focused (deep learning) mainly on the areas of the curriculum that were going to be the focus of assessment. On the other hand, those areas of curriculum that were not included in the assessment were studied lightly (surface learning). It is not only the quantity but also the quality of learning, which is strongly influenced by the mode of assessment. In other words, an assessment process promotes deep learning and, thereby, helps retention of facts and understanding of concepts. However, the understanding of concepts is dependent on how well the assessment is designed and structured. Poorly designed assessment encourages surface learning with short-lived educational outcomes. In fact a quality education is the product of continuous interaction between instruction, curriculum and assessment as suggested by Hamblton and Pitoniak (2006) (fig 1). 


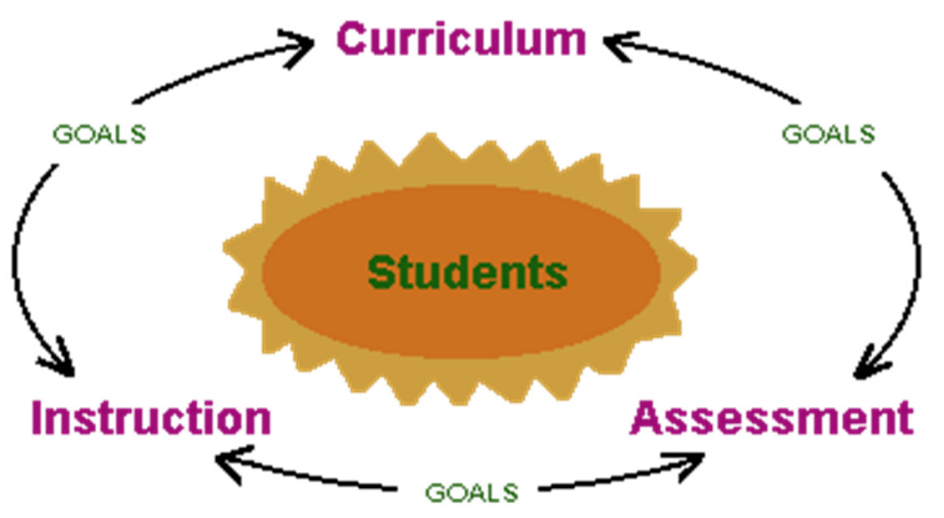

Figure1. The Curriculum-Instruction-Assessment (CIA) Model of Course Development

In our previous article (Halawa et al, 2017) in a previous issue of this journal, we illustrated our experience of designing and conducting a totally online course in clinical transplantation. This course is designed to deliver up-to-date knowledge and state-of-art clinical experience in transplantation reflecting the clinical practice of many UK as well as well-known international centres. Successful completion would lead to award a degree (Diploma/Master) from the University of Liverpool, a Russell group of universities that ensures credibility and quality assurance of the education. Due to the reflective nature of this education we have to structure the assessment to define threshold concepts that the students should be able to understand (Sharma et al, 2017).

Structured assessment is also the most appropriate engine to fine-tune and reform the curriculum. The assessment guides us as tutors to stress on the parts of the curriculum not digested well by our students. It is expected that the teachers do not to waste time and effort in teaching unimportant and irrelevant topics overloading the students. Designing a curriculum without implementing a structured assessment strategy is meaningless and waste of time. In other words, taking a test does not end learning, but just signals the beginning.

When we blueprinted the online master degree in transplantation, we have to think how would we design the assessment. Self-assessment where the student takes the lead of his assessment, peer-assessment where students assess each other based on clearly defined rubrics or implement the standard teacher-led assessment. Do we need to implement different assessment modalities or stick to only one?

\section{Self-assessment}

Implementing self-assessment strategy helps the students to reflect on their own work with the aim to promote their learning process, thereby, achieving the planned learning objectives of this course. It lends itself very well to the formative assessment strategy adopted in this course. In this context, it is not synonymous with self-grading (Weimer, 2010). The course faculty strongly believes that self-assessment is a formative exercise that promotes critical analysis and qualitative evaluation of learning rather than a summative and quantitative function looking at scores and grades to pass the test. This assessment strategy helps the student to identify the gap between the planned and the achieved outcome. McMillan and Hearn, (2008) defined self-assessment accurately as "a process by which students monitor and evaluate the quality of their thinking and behaviour when learning and identify strategies that improve their understanding and skills" (p.40). In this respect, self-assessment aligns closely with standard (criterion)-based assessment rather than the standardized assessment, where student's performance is assessed against his previous performance, a predefined standard or a set score rather than against the performance of peers (Brown, 1988; Anon, 2006).

In transplantation education, self-assessment is an excellent means for testing factual knowledge including understanding of formulae and terminology; also it tests the metacognitive skills; a reflective process fostering deep understanding, critical thinking and reasoning. This strategy lends itself very well to this distance-learning course, where the administration and marking of objective multiple choice questions (MCQ) for self-assessment are easily automated through the university e-blackboard. 


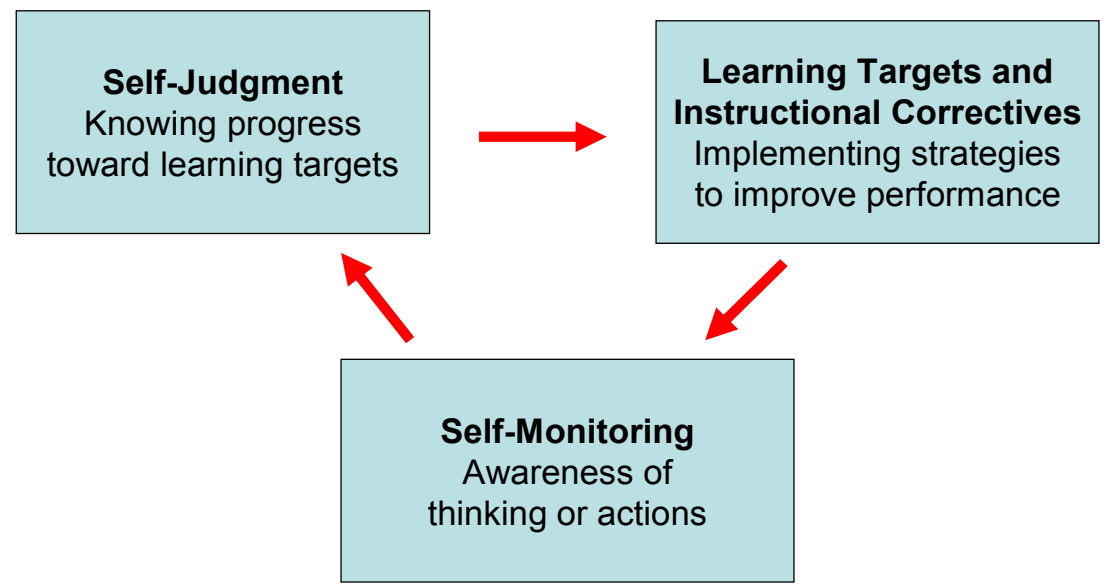

Figure 2. Self-assessment Cycle

McMillan and Hearn (2008) conceptualized self-assessment as a cycle of three components closely related to each other: self-monitoring, self-evaluation, and identification and implementation of required remedies and corrections (Figure 2). Essentially, the students in this course are encouraged to evaluate their learning and performance outcomes, construct their own feedback based on well-defined standards. Then they determine the next steps to improve their performance. This cycle should be repeated to promote the learning process. Mabe and West's (1982) and also Gordon (1991) highlighted the importance of student's experience as an important factor for a successful self-assessment process. Effectiveness of formative assessment is promoted by precise, explicit and timely feedback by the faculty who are well trained in the engaging the students.

We can conclude from the above discussion that self-assessment in this course is an essential driver for effective formative assessment. In fact, Sadler (1989) and Black and William (1998) suggested that self-assessment is the foundation for an effective feedback process. It was not an exaggeration when Black and William suggested that the self-assessment is "a sine qua non for effective learning" (p. 26).

There are two basic strategies for self-assessment (Scott, 2000) that are implemented in this distance learning course: Firstly, self-assessment of task performance using models and/or scoring rubrics. In this respect, the questions are focused on factual knowledge, definitions and undisputed observations. The provided MCQ tests are suitable for this purpose. The availability of online marking schemes makes this possible. Limited response questions provided in the discussion board are also a useful tool as they mainly deal with factual knowledge. We think that, constructed response questions are the most challenging format to assess task performance, as they may be open-ended with multiple solutions, which may affect the validity of the self-assessment. Secondly, the self-assessment is a continuous process as the students in this course react to responses by other students as the reply to the questions posed in relation to management of clinical scenario $(\mathrm{n}=120$ spread over 3 modules) on e-blackboard. This metacognitive self-assessment through reflection is a type of self-assessment that focuses mainly on deep understanding, critical thinking and clinical reasoning. The different formative assessment strategies in this course (poster presentation, mini-review and case scenarios) are designed in a way to test the metacognitive function. We strongly believe that, the most reliable approach is to pose constructed response questions, as we mentioned before, the student participate in discussions and express their assumptions in response to open-ended questions that have multiple solutions. Moreover, portfolio assessment as a future evolution of the course would serve the same purpose.

\section{Shortcomings of Self-Assessment in the Online Distance Education in Transplantation}

Employing the self-assessment strategy does have some inherent flaws, which have been addressed in this course. From experience, not all students are familiar with the process of self-assessment and, therefore, they might be outside their comfort zone. They may believe that this assessment is the duty of the course tutors (Falchikov, 2003) and become reluctant to take this elective form of assessment (Liang, 2014). Students tend to overestimate their knowledge (Shrauger and Osberg, 1981) and underestimate the immense power of reflective exercise. They may not be able to recognize their own deficiencies especially in the written work. Providing the students with checklist is helpful guidance when they mark their own work. As the students may not take it seriously, the self-assessment may 
lose its reliability (Dickinson, 1987). There may be potential for a breach of confidentiality and sense of humiliation on reporting the student own weakness in the virtual class (Dickinson, 1987). Our role as tutors is to provide the necessary education and training in the self-assessment process to bridge these barriers and helps to achieve the learning objectives planned from self-assessment.

\section{Peer-assessment}

In peer-assessment, the students assess the coursework of each other. Peer assessment is an innovation in assessment aiming at empowering the students and improving the quality of education through promotion of reflection (Mowl, 1996; McDowell and Mowl, 1996). Peer-assessment extends beyond marking the coursework to involve setting of the acceptable evidence of achievement and pass marks (Biggs, 1999; Brown et al, 1994).

We see peer-assessment as a powerful tool for motivation that gives the students a sense of ownership of the assessment process. Giving the online nature of this course that deals with ambiguous and complex topic like transplantation, we are reluctant to employ this formative assessment strategy for two main reasons. Firstly, we are concerned about the reliability and validity of this form of assessment due to the difference in the institutional background and variation in experience between the students. In addition, we are not sure about the quality and consistency of the feedback given by the students. We rely on high quality feedback to achieve our educational goals. Heywood (2000) and Stefani (1994) and other investigators demonstrated those students tend to under-mark the coursework compared to tutors. Others found the opposite, where there is a tendency to over-mark (Boud and Holmes, 1995), a dilemma we are keen to avoid in this course. Secondly, underperforming students are unable to assess the coursework of their well-performing peers giving the complex nature of transplantation science. Their judgement may be unrealistic and unfair, and the given feedback may be irrelevant.

\section{Teacher-Led Assessment (TLA)}

The term 'teacher-led assessment' (TLA) is used throughout this document to refer to any assessment activity that is carried out by a teacher in supporting candidates' learning and assessing his/her knowledge based on a well-defined standard/rubrics. The key role played by the tutors involved in the assessment in the course is to identify and deal with the following:

\section{A. Lack of engagement}

Coursework in renal transplantation distance education requires the student to be actively engaged throughout the learning process to achieve the planned learning objectives (Astin, 1993; Pascarella and Terenzini, 1991). Disengagement could be an issue especially when collaborative coursework is required particularly for a group of students with different personal and institutional background. Disengagement is not uncommon. Kuh and colleagues (2000) reported $18 \%$ of these students in 128 institutes were not academically engaged. In transplantation science education, like in any other disciplines, disengagement occurs at different levels, emotional, intellectual and physical (Concordia University, 2014). Getting the student emotionally involved in coursework assessment by providing a strong link to his/her clinical and day-to-day practise in transplantation helps to achieve the learning objectives. Loss of interest during the collaborative work and poor attention can be counteracted by keeping the students intellectually active through the involvement of each member of the group by defining roles for each member of the team. Physical disengagement entails reluctance of some member of the group to seek the planned task including the appropriate use of the available resources such as a library and the provided websites.

As course tutors, we should be able to predict which student will drift away and become disengagement, also which course structure that encourages the disengagement. These tasks would be difficult to achieve if the assessment is purely self or peer assessment. The online nature of the course allows the students to live on their virtual plants separated by time and space encouraging more disengagement. Hu and Kuh, (2000) demonstrated that certain student background characteristics such as race, ethnicity and gender have an influence on the level of engagement. In their interesting study, they showed that white American and Asian have tendency towards disengagement. This factor is important in our online education in transplantation giving its international nature. They also found that men were more likely to be either not engaged at all or highly engaged compared with women. We suspect that the past experience, background knowledge and student preparation have an effect on the level of engagement. Experienced clinicians joining the course and students who have a higher degree in a closely related subject such as urology or nephrology will find it easy to engage in the transplant education particularly in collaborative coursework. There is strong evidence that the level of engagement differs based on their institutional background (Boyer,1989; Kuh and $\mathrm{Hu}, 2001 \mathrm{a})$. Students coming from research institutes are less likely to engage. This is very relevant to this course 
where the course is more clinically oriented. Researchers may find this clinical atmosphere where case-based discussion and clinical scenarios are the main assessment tools. We suspect that students coming from a reputable institute more likely to have a higher level of engagement in collaborative coursework. Course structure also may promote disengagement by having too many periodic assessment deadlines. This has been avoided in this course, where the core education for each module is delivered over 26 weeks. The students can submit his coursework during the next 52 weeks resisting the temptation of delaying learning by having unnecessary many deadlines.

Students who are not engaged throughout the learning process are noted and contacted individually to resolve any issues they might be facing. It is essential to identify these problems and resolve them as soon as they arise to facilitate engagement from the beginning before it is too late (when it comes to the assessment stage). Students, who are distracted by the media of delivery, cannot engage properly.

E-mail addresses for general enquiries and also the contact e-mail of the lead tutor of each module is provided in the original blueprinting of the course (in the course handbook) to help any student having difficulty with the course.

\section{B. Alignment with the national guidelines}

We gave it a special consideration in the original design of the course. Personally we find it also challenging especially when we deal with overseas students and students with different ethnic background. In the context of organ transplantation, patients from Afro-Caribbean origin are known to have a high incidence of diabetes and also are at higher risk of immunological rejection of the transplanted organs. They require special consideration when we plan for organ transplantation. Deceased donor transplantation is not popular in certain countries due to lack of resources and also generates an ethical dilemma in other countries (Japan and the Middle East). There is a high incidence of certain diseases in some parts of the world (HIV in central and southern parts of Africa), which need special attention when we design the immunosuppression protocol. Due to the financial constraints, cheap and less effective immunosuppressive drugs are used in other parts of the world.

It is quite challenging to accommodate these different national guidelines in the curriculum and subsequently in the assessment in case of self and peer assessment. On the other hand, tutors should meet their educational needs suggested Khaleghitabar and colleagues in 2016 in order absorb this diversity in practice. The assessment in transplantation is structured to match the learning objectives in a way not to breach the international guidelines especially for overseas doctors. Also, it is always possible to base the assessment performed by experienced tutor on common ground and mutually agreed knowledge (Clark and Brennen, 1991) rather than diving into a deep sea of disputes and uncertainties.

\section{Managing underperforming students}

Initially, we thought that students fail the assessment due to lack of knowledge and professionalism, but Duffy (2004a) and also Cohen and Rhydderch (2006) highlighted other good reasons for failure. Behavioural issues such as poor communication, lack of interest, failure to engage during the learning process can lead to an unsuccessful outcome especially when collaborative work is assessed (analysis of guidelines and WebQuest). Lack of personal insight into the professional boundaries is an additional cause of concern. These soft skills are essential to be assessed to ensure long-lasting outcome. In fact, they constitute an integral part of the hidden curriculum of this course.

We designed the coursework strategy to test the depth as well as the breadth of knowledge by employing different coursework formats. Equally important, failure to demonstrate sound and professional implementation of this knowledge in line of the national guidelines is considered underperformance. We are always looking at how the student implements rather regurgitate of the knowledge (outcome-based assessment) (Norcini, 2003). Satisfactory outcome in a given treatment plan does not only indicate mortality and morbidity but also highlights other important endpoints such as feasibility of the suggested treatment plan, patient satisfaction, functional status and cost effectiveness. In teacher-led assessment, we are keen for the students to demonstrate multidimensional approach when they design their management plan by looking at the other endpoints mentioned before. For the public, this multidimensional approach provides reassurance that the doctor is performing well in clinical practice. For individual patients, it helps to choose which doctor to trust. For doctors, it provides reassurance that the assessment reflects their real day-to-day practice.

\section{Implement strategies to address underperformance}

In this course, as in many other aspects of life, "prevention is better than cure" is the way forward to avoid such unfavourable outcome. We describe the undergraduate education as a "piece-meal" education, where the tasks are clear and the boundaries are well defined, but the postgraduate arena is different. It requires more understanding and 
maturity from both the students and the tutors about the amount of work required due to the vagueness and lack of clear boundaries in postgraduate education in general and in transplantation science in particular. Underestimating the amount of work required in transplantation science is a major issue that may lead to underperformance. This requires clear explanation to the learners from the outset and to "think outside the box". Also, careful monitoring from module leads is paramount.

We strongly believe that the first sign of underperformance is a lack of engagement. It is quite easy to drift down the disengagement route due to the "virtual classroom" nature of the course, which should be picked up through careful monitoring, and dealt with promptly by identifying barriers to their engagement. Also it is our duty to provide counseling to renew their enthusiasm and to "top up" their motivation by prompt and constructive criticism. The tutor must be aware of the ethnic and socioeconomic background and also the student's personality trait, which we believe have a strong impact on how we should deliver the feedback. Negative feedback is demotivating and not welcomed.

Finally, it is important to address the value of tutor leadership as a driving force for success of this course. Excellent communication between the tutors themselves and between tutors and students, paying attention to the teaching quality improve the leadership and subsequently lead to the success of the course. Tutors acting as discussion leaders, who summarize, explain, debate, and use diagrams to illustrate concepts rather than facilitating particularly for underperforming students improve the learning outcome and improve their performance as pointed by Shield et al (2007).

\section{Conclusion}

There is more to assessment than seeing if the requirements for achieving a qualification have been met. Teachers make professional judgments on learners' performance in every teaching and learning session undertaken, whether consciously or subconsciously. Using these professional judgments and translating them into feedback on the quality of individuals' work is the focus of 'assessment for learning', which is the main objective of our assessment strategy. Self-assessment is also needed to promote teacher-led assessment. The diversity of our students and the international nature of this course is a hurdle in implementing peer-assessment. We conclude that the traditional teacher-led assessment supplemented by self-assessment though with inherent flaws, has been a strong drive in learning process in this on-line course.

\section{References}

Anon (2006) Criterion-based assessment definition. Retrieved from http://www.mondofacto.com/facts/dictionary?criterion-based+assessment

Astin, A. W. (1993). What Matters in College: Four Critical Years Revisited. Jossey-Bass, San Francisco.

Biggs, J.B. (1999). Teaching for Quality Learning at University, Buckingham: SRHE and Open University Press.

Black, P. J., \& Wiliam. D. (1998). Assessment and Classroom Learning. Assessment in Education, 5(1), 7-74. https://doi.org/10.1080/0969595980050102

Boud, D., \& Holmes, H. (1995). Self and peer marking in a large technical subject. In Boud, D. (ed.), Enhancing Learning through Self Assessment, p63-78. London: Kogan Page

Boyer Commission on Educating Undergraduates in the Research University (1998). Reinventing Undergraduate Education: A Blueprint for America's Research Universities. The Carnegie Foundation for the Advancement of Teaching, Stony Brook, New York.

Brown, S. (1988). Criterion referenced assessment: what role for research? In Black, H.D. and Dockerell, W.D. (Eds.), New developments in educational assessment, British Journal of Educational Psychology, Monograph series no. 3, pp. 1-14.

Brown, S., Rust, C., \& Gibbs, G. (1994). Involving students in the assessment process, in Strategies for DiversifyingAssessments in Higher Education, Oxford: Oxford Centre for Staff Development, and at DeLiberations. Cambridge University Press.

Clark, H. H., \& Brennan, S.E. (1991). Grounding in communication. In Resnick, L. B.; Levine, J. M., (eds.), Perspectives on socially shared cognition, American Psychological Association, ISBN 1-55798-376-3.

Cohen, D., \& Rhydderch, M. (2006). Measuring a doctor's performance: personality, health and wellbeing. 
Occupational Medicine, 56, 438-440. https://doi.org/10.1093/occmed/kq1076

Concordia University (2014). Strategies for Engaging Under Performing Students. Retrieved from http://education.cu-portland.edu/blog/curriculum-instruction/strategies-for-engaging-under-performing-students /

Dickinson, L. (1987). Self-instruction in language learning. Cambridge: Cambridge University Press.

Duffy, K. (2004a). Failing students London, Nursing and Midwifery Council. Retrieved from http://www.google.co.uk/url?url=http://www.nmc-uk.org/documents/Archived\%2520Publications/1Research\% 2520papers/Kathleen_Duffy_Failing_Students2003.pdf\&rct=j\&frm $=1 \& q=\&$ esrc $=$ s\&sa $=$ U\&ei $=$ fWefU_BOaP F7Aagv4GYCA\&ved=0CBoQFjAB\&sig2=DefbF7QalH_RRn_LrBWjsw\&usg=AFQjCNH0EgwE2NjGd4sO8 ELKQzwXa50kmA

Falchikov, N. (2003). Involving students in assessment. Psychology, Learning, and Teaching, 3(2), 102-108. https://doi.org/10.2304/plat.2003.3.2.102

Gordon, M. (1991). A review of the validity and accuracy of self-assessments in health professions training. Academic Medicine, 66, 762-769. https://doi.org/10.1097/00001888-199112000-00012

Halawa, A., Sharma, A., \& Bridson, J. M. et al (2017). Distance Learning in Clinical Transplantation; A Successful Model in Post-graduate Education. World Journal of Education, 7(3). https://doi.org/10.5430/wje.v7n3p74

Hambleton, R. K., \& Pitoniak, M. J. (2006). Setting performance standards. In R. L. Brennan (Ed.), Educational measurement (4th Ed.) pp. 89-115. Westport, CT: Praeger.

Heywood J. (2000). Practicals, projects, problem-based learning and portfolios. In Heywood J, (ed.), Assessment in Higher Education. London: Jessica Kingsley Publishers, 316-346.

Khaleghitabar, M., Bahador, H., Bandehagh, A., \& Shoaleh, B. (2016). Educational needs of faculty members of basic sciences of faculty of medicine: educational and personal development needs. Journal of Medical Education Summer, 15(3), 115-23.

Kuh, G. D., Hu, S., \& Vesper, N. (2000). They shall be known by what they do": An activities-based typology of college students. J. Coll. Stud. Dev., 41, 228-244. https://doi.org/10.2307/2649131

Kuh, G., \& Hu, S. (2001a) Learning productivity at research universities. J. Higher Educ., 72, 1-28.

Liang, J. (2014). Toward a three-step pedagogy for fostering self-assessment in a second language writing classroom. The CATESOL Journal, 26(1), 100-119.

Mabe, P., \& West, S. (1982). Validity of self-evaluation of ability: A review and meta-analysis. Journal of Applied Psychology, 67(3), 280-296. https://doi.org/10.1037/0021-9010.67.3.280

McDowell, L., \& Mowl, G. (1996). Innovative assessment - its impact on students, 131-147. In Gibbs, G. (ed.), Improvingstudent learning through assessment and evaluation, Oxford: The Oxford Centre for Staff Development.

McMillan, J.H., \& Hearn, J. (2008). Student Self-Assessment: The Key to Stronger Student Motivation and Higher Achievement. Educational Horizons, 87(1), 40-49.

Mowl, G. (1996). Innovative Assessment, in DeLiberations. Retrieved from http://www.lgu.ac.uk/deliberations/assessment/mowl_content.html

Norcini, J. (2003). Work based assessment. BMJ., 326(7392), 753-5. https://doi.org/10.1136/bmj.326.7392.753

Pascarella, E. T., \& Terenzini, P. T. (1991). How College Affects Students. Jossey-Bass, San Francisco.

Sadler, D. R. (1989). Formative Assessment and the Design of Instructional Systems. Instructional Science, 18(2), 119-144. https://doi.org/10.1007/BF00117714

Scott, J. L. (2000). Authentic assessment tools. In R. Custer (Ed.), Using Authentic assessment in vocational education. Information Series No. 381. Columbus, Ohio: ERIC Clearinghouse on Adult, Career, and Vocational Education.

Sharma, A., Halawa, A., \& Bridson, J. M. et al. (2017). Implementation of Critical Threshold Concept in Clinical Transplantation: A New Horizon in Distance Learning. World Journal of Educational Research, 4(2), 301-12. https://doi.org/10.22158/wjer.v4n2301

Shields, H.M., Guss, D., \& Somers, S.C. et al. (2007). A faculty development program to train tutors to be discussion 
leaders rather than facilitators. Acad Med., 82, 486-492. https://doi.org/10.1097/ACM.0b013e31803eac9f

Stefani, L.A.J. (1994). Peer, Self and tutor assessment: relative reliabilities. Studies in Higher Education, 19(1), 69-75. https://doi.org/10.1080/03075079412331382153

Weimer, M. (2010). Self-Assessment Does Not Necessarily Mean Self-Grading. Retrieved from $\mathrm{http}: /$ www.facultyfocus.com/articles/educational-assessment/self-assessment-does-not-necessarily-mean-self-g rading/ 